[Agr. Biol. Chem., Vol. 31, No. 11, p. 1332 1336, 1967]

\title{
Experiments Directed toward the Total Synthesis of Polycyclic Terpenes
}

\section{Part II. The Synthesis and Some Reactions of 2-Methoxycarbonyl- methyl-3-Methoxycarbonyl-5-Methoxy Indanone"}

\author{
By Tomoya Ogawa and Masanao Matsui \\ Department of Agricultural Chemistry, Faculty of Agriculture, \\ The University of Tokyo, Bunkyo-ku, Tokyo \\ Received June 12, 1967
}

\begin{abstract}
A synthetic sequence for conversion of $m$-methoxy benzaldehyde to 2-methoxycarbonylmethyl-3-methoxycarbonyl-5-methoxy indanone and its reaction with methyl vinyl ketone are described.
\end{abstract}

After synthesizing $( \pm) 7$-deoxyepiallogibberic acid methyl ester norketone $(\mathbf{I})^{1 \prime}$ which has the same B,C,D ring stereochemical behavior as natural gibberellins, we were interested in the synthesis of the gibbane compound (III). The indanone (II) seemed to be a promising intermediate for the synthesis of the compound (III). In this paper the synthesis and the alkylation of the indanone diester (II) are described.

$m$-Methoxybenzaldehyde and diethylmalonate were treated with piperidine-acetic acid in benzene to give the diester (IV) in 95\% yield. The diester (IV) was transformed to the cyanoester which was directly saponified to give the dibasic acid (V) in $80 \%$ yield. The dibasic acid (V) was cyclized in polyphosphoric acid to give in $90 \%$ yield the crude crystalline acid (VI) which was esterified to give the ester (VII) in $61 \%$ yield. The structure of VII was clearly determined by the NMR spectrum which showed three protons signals in the aromatic proton region as 1,2,4substituted pattern; $J_{12}=8$ c.p.s., $J_{24}=2$ c.p.s., $J_{14}=0$ c.p.s.

1) Part I, T. Ogawa and M. Matsui, This Journal, 31, 1327 (1967).
For the purpose of the monoalkylation a C-2 the ester (VII) was acylated with di methylcarbonate and sodium amide in benzen - ether to give an oily product which wa alkylated with methyl bromoacetate an methanolic sodium methoxide in benzene The resulting oily alkylated product wa refluxed in conc. hydrochloric acid-dioxan to give the dibasic acid (VIII) m.p. 174 $175^{\circ} \mathrm{C}$ in $45 \%$ yield from the diester (VII) The dibasic acid was converted into the cor responding dimethyl ester (II) m.p. $97 \sim 98^{\circ} \mathrm{C}$ in methanol containing sulfuric acid in $68{ }_{r}$ yield.

That the alkylation was occurred at C-2 o the ester (VII) was confirmed by the NMI spectrum of (II) which showed the signal o the C-3 proton at $\tau 5.83$ as a doublet, $J=$ c.p.s. And the C-2 methoxycarbonylmethy and the C-3 methoxycarbonyl groups wer regarded as trans since the more stable tran isomer should be obtained under the reactios condition employed.

The reaction of the diester (II) with methy vinyl ketone under basic condition was at tempted with the hope to obtain the ketoaci (IX). But the unexpected product was isolate 
<smiles>COc1ccc2c(c1)C(C(C)=O)[C@H](CC(C)=O)C2C(C)=O</smiles>

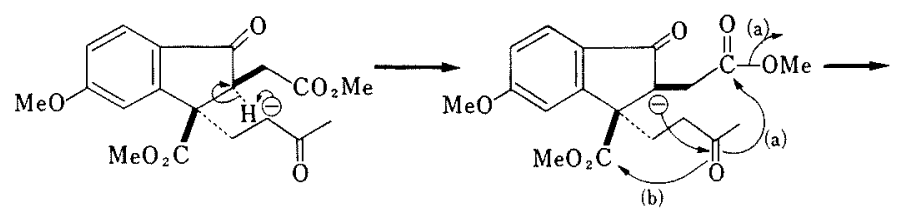

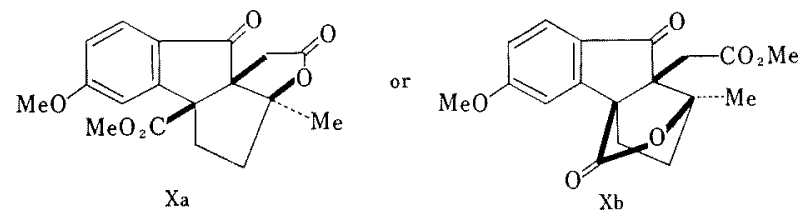

FIG. 1 .

in $36 \%$ yield after the chromatography on alumina of the oil obtained from the above reaction using sodium hydride as a base and anisole as a solvent. This compound ( $\mathrm{Xa}$ or $\mathrm{Xb})$ m.p. $164 \sim 165^{\circ} \mathrm{C}$ showed IR absorption bands at 1775,1740 , and $1710 \mathrm{~cm}^{-1}$ and $U V$ absorption bands at $229(\varepsilon 14,400), 275(\varepsilon 16,200)$, $287(\varepsilon 15,200), 296(\varepsilon 14,400) \mathrm{m} \mu$. These data suggested that this compound had the $r$-lacton function and had the same cojugated chromophore as the diester (II) which showed the UV absorption bands at 224 ( $\varepsilon 16,300), 270$ $(\varepsilon 17,400), 285(\varepsilon 13,700) 293$ ( $\varepsilon 12,300) \mathrm{m} \mu$. The NMR spectrum showed AB pattern signals at $\tau 6.37$ and $7.51, J=19$ c.p.s., two $O-$ methyl singlets at $\tau 6.00$, and 6.25 , one methyl singlet at $\tau 8.70$ and no signal corresponding to the C-3 proton. From these spectral data the structure of this compound was most propably regarded as $\mathrm{Xa}$ or $\mathrm{Xb}$. Since the Dreiding model showed the lactonization seemed to occur more easily to give $\mathrm{Xa}$ than $\mathrm{Xb}$; and the structure $\mathrm{Xa}$ was preferable but the structure $\mathrm{Xb}$ could not be eliminated. The reaction seemed to proceed as shown in Fig. (1).

This reaction revealed that in the case of the indanone ester (II) the carbanion formation occurred at C-3 under the basic condition. As it is known ${ }^{1 \prime}$ that the diester (XI) gave the keto acid (XII) by the reaction with methyl vinyl ketone under the basic condition, it is reasonable to think that in the case of the diester $(\mathrm{XI})$ the carbanion was developed at $\mathrm{C}-2$. This difference in reactivity between II and XI seemed to be due to the bulkiness of the methyl group at C-4 in XI which prevented the maximum overlap between the $p$-electrons of the developing carbanion at C3 and the $\pi$-electrons of the aromatic ring because of the steric repulsion between the methyl group at $\mathrm{C}-4$ and the methoxy carbonyl group at C-3.'

2) D. J. Cram, "Fundamentals of Carbanion Chemistry", Academic Press, 1965, pp. 52 65. 
<smiles>CC(=O)C1C[C@@H]2CC[C@@H](C(=O)C2)c2cccc(C)c21</smiles>

I<smiles>CCOC(=O)C(=Cc1cccc(OC)c1)C(=O)OCC</smiles><smiles>COc1ccc2c(c1)[C@H](C(=O)O)[C@H](CC(=O)O)C2=O</smiles>

VIII<smiles>[R4]C1CC2(C)OC(=O)C13c1cc(OC)ccc1C(=O)C23CC(C)=O</smiles><smiles>COc1ccc2c(c1)C(CC(C)=O)(CC(C)=O)CC2=O</smiles>

X四<smiles>COc1ccc2c(c1)C(C(C)=O)C(CC(C)=O)C2=O</smiles>

II<smiles>COC(=O)[C@H]1c2cc(OC)ccc2[C@@H]2CC[C@](C)(C(C)=O)C[C@]21C</smiles>

III<smiles>COc1cccc(C(CC(=O)O)C(=O)O)c1</smiles><smiles>[R]C([R])C1CC(=O)c2ccc(OC)cc21</smiles><smiles>COc1ccc2c(c1)C(C(=O)O)C1(CC(=O)O)CCC(=O)C=C21</smiles>

IX<smiles>CC(=O)CC1C(=O)c2cccc(C)c2C1C(C)=O</smiles>

XI<smiles>CC(=O)C1CC(=O)c2ccccc21</smiles>

XIV

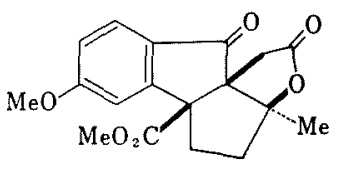

$\mathrm{X}$ a<smiles>Cc1cccc2c1C(C(=O)O)C1(CC(=O)O)CCC(=O)C=C21</smiles><smiles>CC(=O)CC1(C(C)=O)CC(=O)c2ccccc21</smiles>

XV

CHART

In order to make clear the substituent effect on the alkylation of these indanone esters, the alkylation of the ester (VII) and (XIV) were further studied. The ester (VII) was directly alkylated with methyl bromoacetate using sodium methoxide as a base and transformed into the diester (XIII), different from the diester (II), in $45 \%$ yield. The structure of this isomeric diester (XIII) was confirmed by the NMR spectrum which showed two AB pattern

3) K. Mori, M. Matsui and Y. Sumiki, This Journal, 27, 27 (1963). signals at $\tau 6.38,7.35, J=19$ c.p.s. and at $\tau 6.50,7.33, J=17$ c.p.s., partly overlaped with O-methyl singlet. This two $A B$ pattern signals became clearly visible when the spectrum was taken in benzene, $\tau 6.26,7.43$, $J=19$ c.p.s.; $\tau$ 6.67, 7.73, $J=17$ c.p.s.

The indanone ester (XIV) ${ }^{3}$ having no substituent on the aromatic ring was also directly alkylated with methyl bromoacetate using sodium methoxide as a base to give the ketodiester (XV), the structure of which was demonstrated by the NMR spectum showing two $\mathrm{AB}$ pattern signals at $\tau 6.50,7.45, J=21$ 
c.p.s. and $\tau 6.52,7.40, J=17$ c.p.s. These results showed that 3-methoxycarbonyl indanones without methyl group at C-4 were more easily alkylated at C-3 than at C-2 and that the specificity of these alkylation was reasonably due to the steric repulsion between the methyl group at $\mathrm{C}-4$ and the methoxycarbonyl group at C-3.

\section{EXPERIMENTAL}

All melting points are uncorrected. Infrarred spectra were measured as Nujol mulls for solid samples and as films for liquid samples, unless otherwise stated. Ultraviolet spectra were determined for ethanol solutions. NMR spectra were determined at $60 \mathrm{Mc}$ in deuteriochloroform using tetra-methylsilane as an internal reference.

Ethyl $m$-methoxybenzalmalonate (IV). mMethoxy benzaldehyde $(710 \mathrm{~g})$ and diethyl malonate $(1 \mathrm{~kg})$ were refluxed in benzene $(2 \mathrm{l})$ with piperidine $(25 \mathrm{~g})$ and acetic acid $(25 \mathrm{ml})$ with continuous removal of water for ten hrs. The benzene layer was washed by aq. sodiumbicarbonate, dil. hydrochloric acid and saturated saline successively. Distillation of the product gave an oil, b.p. $170 \sim 195^{\circ} \mathrm{C}(4 \mathrm{mmHg})$, $1370 \mathrm{~g}$, yield 95\%. Anal. Found: C, 64.57; H, 6.50. Calcd. for $\mathrm{C}_{15} \mathrm{H}_{18} \mathrm{O}_{5}$ : C, 64.73; H, 6.520\%. $\nu_{\text {max }}$ $1730,1634,1600,1584 \mathrm{~cm}^{-1}$.

m-Methoxyphenylsuccinic acid (V). Malonate (IV, $690 \mathrm{~g}$ ) in $990^{\circ}$ ethanol (2l) and potassium cyanide $(165 \mathrm{~g})$ in water $(200 \mathrm{ml})$ was refluxed with stirring for $18 \mathrm{hrs}$. Ethanol and water were removed in vacuo. The residue was refluxed in $6 \mathrm{~N}$-aq. potassium hydroxide for $16 \mathrm{hrs}$. After cooling, the mixture was poured into ice-sulfuric acid. Crystalline product was corrected, $443 \mathrm{~g}$, yield $80 \%$. Recrystallization from aq. methanol, m.p. $178 \sim 180^{\circ} \mathrm{C}$. Anal. Found: C, 58.60; H, 5.37. Calcd. for $\mathrm{C}_{11} \mathrm{H}_{12} \mathrm{O}_{5}$ : C, $58.92 ; \mathrm{H}, 5.40 \%$. $\nu_{\max } 1710,1607,1500 \mathrm{~cm}^{-1} . \nu_{\text {nax }}$ 224 (sh. $\varepsilon 8,700$ ), 270 ( $\varepsilon 2,500) \mathrm{m} \mu$.

3-Carboxy-5-methoxy indanone (VI). Dibasic acid $(\mathrm{V}, 250 \mathrm{~g}$ ) was stirred in polyphosphoric acid (from phosphorus pentoxide $1.5 \mathrm{~kg}$ and $85 \%$ phosphoric acid (l) at $95 \sim 100^{\circ} \mathrm{C}$ for $50 \mathrm{~min}$. The resulting slurry was poured into ice $(4 \mathrm{~kg})$ and the crystals were corrected, $207 \mathrm{~g}$, yield $90 \%$. Recrystallization from acetone, m.p. $187 \sim 188^{\circ} \mathrm{C}$. Anal. Found: C, 64.03; H, 4.91. Calcd. for $\mathrm{C}_{11} \mathrm{H}_{10} \mathrm{O}_{4}: \mathrm{C}, 64.07 ; \mathrm{H}$, $4.89 \%$. $\nu_{\max } 1700,1600,1490,1290,1260,1230,1087$,
$930 \mathrm{~cm}^{-1} . \lambda_{\max } 223(\varepsilon 14,500), 267 \quad(\varepsilon 15,000), 283$ (sh. $\varepsilon 11,100), 294(\varepsilon 9,900) \mathrm{m} \mu$.

3-Methoxycarbonyl-5-methoxy indanone (VII). Acid (VI, $83 \mathrm{~g}$ ) was refluxed in methanol $(500 \mathrm{ml})$ with sulfuric acid $(1 \mathrm{ml})$ for $10 \mathrm{hrs}$. Evaporation of methanol to the half volume and on cooling crystals $(54 \mathrm{~g})$ was obtained in yield of $61 \%$. Recrystallization from methanol, m.p. $117 \sim 118^{\circ} \mathrm{C}$. Anal. Found: C, 65.02; H, 5.57. Calcd. for $\mathrm{C}_{12} \mathrm{H}_{12} \mathrm{O}_{4}$ : C, 65.44; H, 5.49\%. $\nu_{\max } 1740,1710,1690,1605$, $1580, \quad 1109 \mathrm{~cm}^{-1}, \quad \tau 2.0 \sim 2.9\left(3 \mathrm{H} ; J_{4 \mathrm{H}, 6 \mathrm{H}}=2\right.$ c.p.s., $J_{6 \mathrm{~B}, 7 \mathrm{H}}=8$ c.p.s., $\left.J_{4 \mathrm{H}, 7 \mathrm{H}}=0\right), 5.63(1 \mathrm{H}$; quartet $J=4$, 7 c.p.s.) 5.97 ( $3 \mathrm{H}$; singlet), 6.10 ( $3 \mathrm{H}$; singlet), $6.5 \sim$ $7.35\left(2 \mathrm{H} ; \mathrm{AB}\right.$ part of $\mathrm{ABX}$ system, $J_{\mathrm{AB}}=18, J_{\mathrm{AX}}=4$, $J_{\mathrm{BX}}=7$ c.p.s.).

2-Carboxymethyl-3-carboxy-5-methoxy indanone (VIII). To the suspension of sodium amide (from sodium $45 \mathrm{~g}$ ) in ether $(300 \mathrm{ml})$ was added dropwise the benzene solution $(400 \mathrm{ml})$ of dimethylcarbonate $(180 \mathrm{~g}$ ) and the ester (VII, $130 \mathrm{~g}$ ) under reflux during $8 \mathrm{hrs}$. After the mixture was left to stand overnight at room temperature, acetic acid $(300 \mathrm{ml})$ and ice were added. The organic layer was washed with water and dried over magnesium sulfate. Evaporation of the solvent gave an oil $(125 \mathrm{~g})$. The oil was dissolved in dry benzene $(600 \mathrm{ml})$ and mixed with methanolic sodium methoxide (sodium $11 \mathrm{~g}$, methanol $150 \mathrm{ml})$. To the resulting mixture methyl bromoacetate $(70 \mathrm{~g})$ was added. Further stirring and refluxing were continued for $3 \mathrm{hrs}$. After the mixture was left to stand overnight at room temperature, water was added and benzene layer was concentrated to give an oil $(144 \mathrm{~g})$. This oil was refluxed in conc. hydrochloric acid $(400 \mathrm{ml})$ and dioxane $(200 \mathrm{ml})$ for $15 \mathrm{hrs}$. While hot, the solution was treated with active carbon and filtered. The filtrate was extracted with ethylacetate. The organic layer was washed with water and concentrated to give an oil which gave crystals $(71 \mathrm{~g})$ by trituration with ether. Yield $45 \%$. Recrystallization from acetone $-n$-hexane, m.p. $174 \sim 157^{\circ} \mathrm{C}$. Anal. Found: C, 59.24; H, 4.77. Calcd. for $\mathrm{C}_{13} \mathrm{H}_{12} \mathrm{O}_{6}: \quad \mathrm{C}, 59.09 ; \mathrm{H}, 4.58 \%$. $\nu_{\max } 1720,1710$, $1600,1500,1295 \mathrm{~cm}^{-1} . \lambda_{\max } 223(\varepsilon 14,000), 268(\varepsilon$ 15,900 ), 284 (sh. $\varepsilon 11,900$ ), 293 (sh. $\varepsilon 10,500$ ).

2-Methox y carbony lmethyl-3-methox y carbony l-5methoxy indanone (II). Ketoacid (VIII, 20 g) was refluxed in methanol $(200 \mathrm{ml})$ with sulfuric acid $(1 \mathrm{ml})$ for 6 hrs. After cooling, precipitated crystals were corrected $(15 \mathrm{~g})$, yield $68 \%$. Recrystallization from methanol, m.p. $97 \sim 98^{\circ} \mathrm{C}$. Anal. Found: C, 61.44; 
$\mathrm{H}$, 5.62. Calcd. for $\mathrm{C}_{15} \mathrm{H}_{16} \mathrm{O}_{6}: \mathrm{C}, 61.64 ; \mathrm{H}, 5.52 \%$. $\nu_{\max } 1748,1703,1608,1500 \mathrm{~cm}^{-1} . \quad \lambda_{\max } 224(\varepsilon 16,300)$, $270(\varepsilon 17,400$ ), 285 (sh. $\varepsilon 13,700$ ), 293 (sh. $\varepsilon 12,300$ ). $\tau 2.1 \sim 3.0\left(3 \mathrm{H} ; J_{4 \mathrm{H}, 6 \mathrm{HI}}=2, J_{6 \mathrm{H}, 7 \mathrm{H}}=8, J_{4 \mathrm{H}, 7 \mathrm{H}}=0\right.$ c.p.s. $)$, 5.83 ( $1 \mathrm{H}$; doublet, $J=4$ c.p.s.), 6.04 ( $3 \mathrm{H}$; singlet), $6.10(3 \mathrm{H}$; singlet), $6.28(3 \mathrm{H} ;$ singlet $), 6.4 \sim 7.2(3 \mathrm{H}$; multiplet).

( \pm ) $2 \beta$-Carboxymethy $1-3 \beta$-methox y carbon y l-5methoxy-8 $\alpha$-methy $1-8 \beta$-oxy-2,3-propano indanone $\mathbf{2} \rightarrow \mathbf{8}$ lactone (Xa). The diester (II, $500 \mathrm{mg}$ ) and $50 \%$ sodium hydride $(200 \mathrm{mg})$ were stirred in dry anisol $(15 \mathrm{ml})$ at $15 \sim 20^{\circ} \mathrm{C}$ for $15 \mathrm{~min}$. To this solution was added dropwise methyl vinyl ketone $(200 \mathrm{mg})$ in anisol $(5 \mathrm{ml})$ at $30 \sim 30^{\circ} \mathrm{C}$ during $30 \mathrm{~min}$. The mixture was further stirred for $1 \mathrm{hr}$, neutralized with acetic acid, diluted with water and extracted with ethylacetate. Evaporation of the solvent gave an oil which was chromatographed over alumina ( $10 \mathrm{~g}$ ). Elution with benzene-ethylacetate $(10: 1)$ gave crystals $(200 \mathrm{mg})$. Yield $36 \%$. Recrystallization from methanol or ethylacetate-n-hexane, m.p. $164 \sim 165^{\circ} \mathrm{C}$. Anal. Found: $\mathrm{C}, 65.70 ; \mathrm{H}, 5.79$. Calcd. for $\mathrm{C}_{18} \mathrm{H}_{18} \mathrm{O}_{6}$ : C, 65.44; H, 5.49\%. $\nu_{\max } 1775,1740,1710,1610$, $1590,1495 \mathrm{~cm}^{-1}$. $\lambda_{\max } 229(\varepsilon 14,400), 275(\varepsilon 16,200)$, $287(\varepsilon 15,200), 296(\varepsilon 14,400) . \quad \tau 2.0 \sim 3.0\left(3 \mathrm{H} ; J_{4 \mathrm{H}, 6 \mathrm{H}}=\right.$ $2, J_{6 \mathrm{H}, 7 \mathrm{H}}=8, J_{4 \mathrm{H}, 7 \mathrm{H}}=0$ c.p.s. $), 6.00$ ( $3 \mathrm{H}$; singlet $), 6.25$ (3H; singlet), 6.37 ( $1 \mathrm{H}$; doublet, $J=19$ c.p.s.), 7.51 ( $1 \mathrm{H}$; doublet, $J=19$ c.p.s.), $7.0 \sim 8.5$ ( $4 \mathrm{H}$; multiplet), 8.70 ( $3 \mathrm{H}$; singlet).

3-Methox y carbon y l-3-methox y carbon y lmeth y 1-5methoxy indanone (XIII). Ester (VII, $1.1 \mathrm{~g}$ ) was dissolved in methanolic sodium methoxide (sodium $130 \mathrm{mg}$ and methanol, $20 \mathrm{ml}$ ) and the mixture was kept at $40^{\circ} \mathrm{C}$ for $30 \mathrm{~min}$. Methyl bromoacetate (750 $\mathrm{mg}$ ) in methanol $(5 \mathrm{ml})$ was added dropwise at $15^{\circ} \mathrm{C}$. The mixture was left to stand at room temperature for $1 \mathrm{hr}$, and then refluxed for $10 \mathrm{~min}$. After cooling, the mixture was diluted with water, extracted with ethylacetate and concentrated to give crystals by trituration with ether $(650 \mathrm{mg})$. Yield $45 \%$. Recrystallization from ethylacetate- $n$-hexane, m.p. $134 \sim 137^{\circ} \mathrm{C}$. Anal. Found: C, 61.84; H, 5.48. Calcd. for $\mathrm{C}_{15} \mathrm{H}_{16} \mathrm{O}_{6}$ : C, 61.64; H, 5.52\%. $\nu_{\max } 1735,1705$, 1603, $1496 \mathrm{~cm}^{-1} . \lambda_{\max } 225(\varepsilon 17,400), 269(\varepsilon 16,900)$, 284 (sh. $\varepsilon$ 12,800), 293 (sh. $\varepsilon 10,300$ ). $\quad \tau 2.3 \sim 3.2(3 \mathrm{H}$; multiplet), 6.10 (3H; singlet), 6.29 (3H; singlet), 6.31 ( $3 \mathrm{H}$; singlet), 6.38 ( $1 \mathrm{H}$; doublet, $J=19$ c.p.s.), 6.50 (1H; doublet, $J=17$ c.p.s.), 7.33 ( $1 \mathrm{H}$; doublet, $J=17$ c.p.s.), 7.35 ( $1 \mathrm{H}$; doublet, $J=19$ c.p.s.); $\tau$ (in benzene) 6.26 ( $1 \mathrm{H}$; doublet, $J=19$ c.p.s.), 6.67 ( $1 \mathrm{H}$; doublet, $J=17$ c.p.s.), 6.77 ( $3 \mathrm{H}$; singlet), 6.85 ( $3 \mathrm{H}$; singlet), 6.87 ( $3 \mathrm{H}$; singlet), 7.43 ( $\mathrm{HH}$; doublet, $J=19$ c.p.s.), 7.73 ( $1 \mathrm{H}$; doublet, $J=17$ c.p.s.).

3 - Methox y carbony $\mathbf{~ - ~} \mathbf{3}$ - methox y carbon y lmeth y $\mathbf{l}$ indanone (XV). Ester (XIV, $10 \mathrm{~g}$ ) in benzene (150 $\mathrm{ml}$ ) and methanolic sodium methoxide (sodium $1.2 \mathrm{~g}$ and methanol $20 \mathrm{ml}$ ) were mixed at room temperature. To the resulting mixture was added dropwise methyl bromoacetate $(8 \mathrm{ml})$ with stirring. The mixture was refluxed for $1.5 \mathrm{hrs}$. Distillation of the product gave an oil, b.p. $137 \sim 150^{\circ} \mathrm{C}(0.05 \mathrm{mmHg})$, $2.3 \mathrm{~g}$. By trituration with methanol crystals were obtained, $1.6 \mathrm{~g}$, yield $12 \%$. Recrystallization from methanol, m.p. $101 \sim 103^{\circ} \mathrm{C}$. Anal. Found: C, 64.15; $\mathrm{H}, 5.56$. Calcd. for $\mathrm{C}_{14} \mathrm{H}_{14} \mathrm{O}_{5}$ : C, 64.11; H, 5.38\%. $\nu_{\max } 1735,1725,1595,1210,1194,1168 \mathrm{~cm}^{-1}$. (in carbontetrachloride) $2.2 \sim 2.8$ ( $4 \mathrm{H}$; multiplet), 6.28 ( $3 \mathrm{H}$; singlet), 6.30 ( $3 \mathrm{H}$; singlet), 6.50 ( $1 \mathrm{H}$; doublet, $J=21$ c.p.s.), 6.52 ( $1 \mathrm{H}$; doublet, $J=17$ c.p.s.), 7.40 (1H; doublet, $J=17$ c.p.s.), 7.45 ( $1 \mathrm{H}$; doublet, $J=$ 21 c.p.s.). 